\title{
Comparison of hepatitis $E$ virus seroprevalence between HBsAg-positive population and healthy controls in Shandong province, China
}

$\mathrm{Li}_{\text {Zhang }}{ }^{1,2 \dagger}$, Zechun Jiang ${ }^{3 \dagger}$, Jingjing Lv², Jiaye Liu², Bingyu Yan², Yi Feng ${ }^{2}$, Li Li ${ }^{4}$, Guomin Zhang ${ }^{4}$, Fuzhen Wang ${ }^{4}$ and Aiqiang $\mathrm{Xu}^{1,2^{*}}$

\begin{abstract}
Background: Persons with chronic hepatitis B (CHB) infection were reported to suffer severe disease after hepatitis E virus (HEV) superinfection, but the studies regarding HEV seroprevalence in this population were limited. A recent study in Vietnam found higher HEV seroprevalence among CHB patients compared with healthy controls.

Methods: A community-based case-control study was conducted in two counties of Shandong province, China, where hepatitis $E$ incidence was at the highest (Rushan) and lowest (Zhangqiu) in the province based on data from routine public health surveillance. Four townships were selected randomly from each county and all residents in these townships were tested for hepatitis B surface antigen (HBsAg). Those tested positive for HBsAg (CHB group) and the 1:1 age and sex-matched HBsAg-negative residents (control group) were included. Anti-HEV IgM and IgG were tested and positive rates of IgG and IgM were compared between the CHB group and the control group.

Results: In total, 2048 CHB participants and 2054 controls were included in the study. In the CHB group, HEV IgG seroprevalence was 9.16\% (95\% Cl: 7.47-11.09) in Zhangqiue and 38.06\% (95\% Cl: 35.07-41.19) in Rushan $(P<0.001)$; the corresponding rates of IgM were $0.1 \%(95 \% \mathrm{Cl}: 0.002-0.54)$ and $1.57 \%(95 \% \mathrm{Cl}: 0.90-2.53)$, respectively $(P<0$. 001). HEV IgG seroprevalence was similar between CHB group and the control group in both counties $(P=0.21$, $P=0.47$, respectively) and the same results were found for the positive rate of $\lg M(P=0.103, P=0.262$, respectively). Multivariable analysis showed the status of $\mathrm{HBsAg}$ was not independently associated with the status of anti-HEV IgG in either Zhangqiu or Rushan $[P=0.187, O R=1.23(95 \% \mathrm{Cl}: 0.90,1.68) ; P=0.609$, $O R=1.05$ (95\% Cl: 0.87, 1.26)].

Conclusions: The seroprevalence of HEV varies greatly in different geographic areas, but the seroprevalence is similar between populations with and without CHB. CHB patients residing in high HEV endemic areas might be at higher risk for HBV-HEV superinfection.
\end{abstract}

Keywords: Hepatitis E virus, Chronic hepatitis B, Seroprevlance, Superinfection

\footnotetext{
* Correspondence: aqxuepi@163.com

${ }^{\dagger}$ Equal contributors

${ }^{1}$ Academy of Preventive Medicine, Shandong University, Jinan, China

${ }^{2}$ Shandong Provincial Key Laboratory of Infectious Disease Control and

Prevention, Shandong Center for Disease Control and Prevention, Jinan,

China

Full list of author information is available at the end of the article
} 


\section{Background}

Hepatitis E virus (HEV) was discovered in 1980's and has been documented to be prevalent in many countries [1]. HEV seroprevalence among the general population was $1.95 \%$ in the Netherlands [2], 5.3\% in Japan [3] and $21 \%$ in the United States [4]. HEV is among the leading causes of acute viral hepatitis in developing countries [5] and is responsible for approximately 56,600 deaths in the world annually [6]. HEV infection is often asymptomatic, however in some special populations including pregnant women, patients with chronic hepatitis and those who are immunosuppressed, it might cause severe disease or chronic infection [7-9].

Although HEV is primarily transmitted by the faecaloral route, its transmission by transfusion has already been documented [5]. HEV RNA was detected in $0.001 \%$ to $0.33 \%$ of blood donors in Australian, the United States and Qatar [10-12], suggesting the risk of HEV infection through transfusion. It is well known that hepatitis B and C could also be transmitted by transfusion. The studies from Turkey and Sweden found the seroprevalence of HEV was significantly higher among chronic hepatitis $\mathrm{C}$ patients compared with the general population [13, 14]. A study in Vietnam found significantly higher seroprevalence of $\mathrm{HEV}$ among chronic hepatitis $\mathrm{B}(\mathrm{CHB})$ patients [15], while the study in France found no difference [16].

Both hepatitis B and hepatitis E are endemic in China. The seroprevalence of hepatitis B surface antigen (HBsAg) and anti-HEV IgG was $7.18 \%$ and $23.1 \%$, respectively according to a national survey in 2006 [17, 18]. The estimated number of persons with $\mathrm{CHB}$ is up to 90 million in China [17]. Although the superinfection of HBV and HEV has been widely reported in China [19, 20], all available studies are hospital-based focusing on clinical outcomes after superinfection. HEV seroprevalence among persons with $\mathrm{CHB}$ is poorly understood in China.

We conducted this study to evaluate HEV seroprevalence among persons with and without $\mathrm{CHB}$ in Shandong province, China.

\section{Methods}

\section{Study population}

Shandong province is located in eastern China. The province has 140 counties and a population of 97 million. The average seroprevalence of anti-HEV IgG was $11 \%$ among the general population [21]. This study was conducted during April and July 2014. The study population was selected by two-stage sampling method. First, all counties were ranked by HEV incidence reported through China National Notifiable Disease Reporting System (NNDRS) in 2013 and the county with the highest (Rushan) and the lowest (Zhangqiu) HEV incidence were selected. Second, four townships were selected by simple random sampling from each county. All residents in these townships were tested for HBsAg. All HBsAg-positive inhabitants and 1:1 age and sexmatched inhabitants negative for HBsAg were included in the study. The study flow chart is shown in Fig. 1.

\section{Questionnaire survey}

A face-to-face interview was conducted by the staff from the county level Center for Disease Control and Prevention (CDC). The information was collected on age, gender, education attainment, special occupations (seafood cultivation, processing and selling; swine laughter or selling), health habits including washing hands before dining, drinking boiled water and not-eating out of home and the histories of chronic diseases such as hypertension, heart disease, stroke, etc.

\section{Sample collection and testing}

Blood samples of $5 \mathrm{ml}$ were collected from each participant. HBsAg was detected using Xinchuang ELISA kits (Xinchuang Biology Co., Xiamen, China). Anti-HEV IgG and IgM were detected using the Wantai ELISA kits (Wantai Biology Co., Beijing, China). HEV RNA was tested by real-time PCR for the serum positive for antiHEV IgM (Invitrogen, one step qRT-PCR system). All tests were performed following the manufacturers' instructions and were conducted by staff at Shandong Provincial CDC.

\section{Medical examination for HBsAg-positive participants}

Further medical examination was carried out for HBsAg-positive participants in local hospitals, including physical examination, Ultrasound examination of liver, testing of HBV serological markers including antibody against HBsAg (anti-HBs), antibody against hepatitis B core antigen (anti-HBc), hepatitis $\mathrm{B}$ e antigen (HBeAg) and antibody against hepatitis B e antigen (anti-HBe), and HBV DNA level and Alanine aminotransferase (ALT) level. The participants were classified into HBV carrier, $\mathrm{CHB}$ patients, cirrhosis and hepatocellular carcinoma (HCC) according to the above medical examination. HBV carrier was defined as: (1) Tested positive for HBsAg; (2) had no signs and symptoms suggestive of hepatitis; (3) ALT level was within normal limit (<40 IU/ml) [22]; (4) B ultrasound examination did not find any abnormalities in the liver. A case of chronic hepatitis patient was defined as: (1) HBsAg seropositive status lasted for 6 months or beyond; (2) had signs and symptoms suggestive of hepatitis; (3) HBV DNA was positive and ALT level increased $(\geq 40 \mathrm{IU} / \mathrm{ml})$ and (4) B ultrasound examination showed chronic liver disease. Cirrhosis and HCC were diagnosed mainly according to ultrasound findings. 


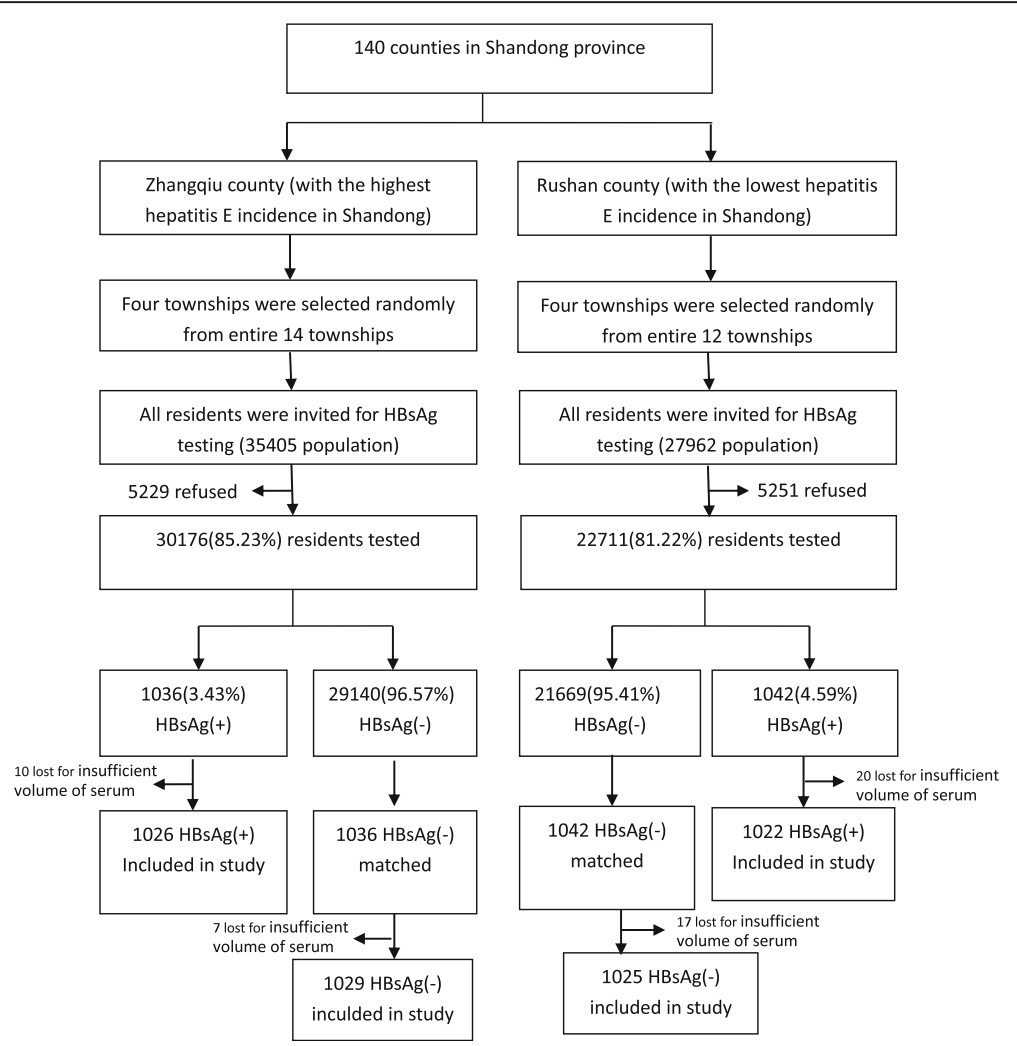

Fig. 1 Study participant flow chart

\section{Statistical analyses}

The seroprevalence of anti-HEV IgG and IgM across different groups was assessed with Pearson Chi-square test, trend Chi-square test and fisher's exact test as appropriate. Multivariable logistic regression model was built to estimate the independent association between status of anti-HEV IgG and HBsAg. The analyses were conducted with STATA 10.0 and the $P$ value $<0.05$ was considered to be statistically significant.

\section{Ethical issues}

This study was approved by Ethics Committee of Shandong Provincial CDC and a written informed consent form was signed by each participant.

Table 1 Demographic characteristics of HBsAg positive and negative participants in Zhangqiu and Rushan county, Shandong province, China

\begin{tabular}{|c|c|c|c|c|c|c|}
\hline & \multicolumn{3}{|l|}{ Zhangqiu county } & \multicolumn{3}{|l|}{ Rushan county } \\
\hline & $\begin{array}{l}\text { HBsAg-positive group } \\
\text { (number, \%) }\end{array}$ & $\begin{array}{l}\text { HBsAg-negative group } \\
\text { (number, \%) }\end{array}$ & $P$ value & $\begin{array}{l}\text { HBsAg-positive group } \\
\text { (number, \%) }\end{array}$ & $\begin{array}{l}\text { HBsAg-negative group } \\
\text { (number, \%) }\end{array}$ & $P$ value \\
\hline Total & $1026(100.00)$ & 1029 (100.00) & & $1022(100.00)$ & $1025(100.00)$ & \\
\hline \multicolumn{7}{|l|}{ Age (yrs) } \\
\hline Under 30 & $57(5.56)$ & $40(3.89)$ & 0.232 & $66(6.46)$ & $72(7.02)$ & 0.462 \\
\hline $30-39$ & 161(15.69) & $170(16.52)$ & & 79(7.73) & 79(7.71) & \\
\hline $40-49$ & $284(27.68)$ & 275 (26.72) & & $242(23.68)$ & 237 (23.12) & \\
\hline $50-59$ & $226(22.03)$ & $234(22.74)$ & & 336 (32.88) & 331 (32.29) & \\
\hline $60-69$ & 196 (19.10) & $200(19.44)$ & & $211(20.65)$ & $222(21.66)$ & \\
\hline Above 70 & $102(9.94)$ & $110(10.69)$ & & 88 (8.61) & $84(8.20)$ & \\
\hline \multicolumn{7}{|l|}{ Gender } \\
\hline Male & $520(50.68)$ & $529(51.41)$ & 0.742 & $516(50.49)$ & 525 (51.22) & 0.471 \\
\hline Female & 506 (49.32) & 500 (48.59) & & 506 (49.51) & 500 (48.78) & \\
\hline
\end{tabular}




\section{Results}

Demographic characteristics of the participants

As shown in Tables 1, 1026 HBsAg-positive participants (age: $51.13 \pm 13.42$ years, age range: $6-85$ years) and $1029 \mathrm{HBsAg}$-negative participants (51.62 \pm 13.40 years, age range: 8-92 years) were included in the analysis in Zhangqiu. The corresponding numbers of participants were 1022 (52.11 \pm 13.07 years, age range: $8-80$ years) and 1025 (51.63 \pm 13.65 years, age range: $5-86$ years) in Rushan. No significant differences were found in age and gender between $\mathrm{HBsAg-positive} \mathrm{and} \mathrm{HBsAg-}$ negative group in both counties (Zhangqiu: $P=0.232$, 0.742; Rushan: $P=0.462,0.471)$. In Zhangqiu, the HBsAg-positive group was consisted of $658 \mathrm{HBV}$ carriers, 102 chronic hepatitis, 22 cirrhotic cases, 1 HCC case and 243 participants with unknown clinical type. In Rushan, the corresponding numbers were 838, 74, 8, 3 and 99 .

\section{Anti-HEV lgG seroprevalence among HBsAg-positive individuals}

HEV IgG seroprevalence was 9.16\% (95\% CI 7.47-11.09) in $\mathrm{CHB}$ group in Zhangqiu and was lower in comparison with that in Rushan (38.06\%, $P<0.001)$. IgG seroprevalence increased with age in both counties $(P<0.01)$, although the seroprevalence was significantly higher in Rushan than in Zhangqiu in all age groups except those above 70 years $(P<0.05)$. IgG seroprevalnce was similar in males and females in Zhangqiu $(P=0.938)$, but was significantly different in Rushan $(P<0.001)$. The rate was much higher among HBV carriers in Rushan than in Zhangqiu $(P<0.001)$ and the same result was observed among hepatitis cases $(P<0.001)$. No significant difference in HEV IgG seroprevalence was found among different $\mathrm{CHB}$ groups in Zhangqiu $(P=0.714)$ and the same result was found in Rushan $(P=0.267)$. The details are shown in Tables 2, 3 and Fig. 2.

Table 2 Seroprevalence of hepatitis E IgG in HBsAg-positive group and HBsAg- negative group by age and gender in Zhangqiu and Rushan

\begin{tabular}{|c|c|c|c|c|c|}
\hline & \multicolumn{2}{|c|}{ HBsAg-positive group } & \multicolumn{2}{|c|}{ HBsAg-negative group } & \multirow[t]{2}{*}{$P$ value ${ }^{\# *}$} \\
\hline & Number detected & Positive, $n(\%, 95 \%$ Cl) & Number detected & Positive, $n(\%, 95 \%$ Cl) & \\
\hline \multicolumn{6}{|c|}{ Zhangqiu county } \\
\hline Total & 1026 & $94(9.16,7.47-11.09)$ & 1029 & $112(10.88,9.05-12.95)$ & 0.21 \\
\hline \multicolumn{6}{|l|}{ Age (yrs) } \\
\hline $0-$ & 53 & $0(0.00,0-6.72)$ & 38 & $4(10.53,2.94-24.80)$ & 0.03 \\
\hline $30-$ & 157 & $5(3.18,1.04-7.28)$ & 167 & $7(4.19,1.70-8.44)$ & 0.77 \\
\hline $40-$ & 275 & $18(6.55,3.92-10.15)$ & 275 & $21(7.64,4.79-11.44)$ & 0.74 \\
\hline $50-$ & 232 & $10(4.31,2.09-7.78)$ & 237 & $24(10.13,6.60-14.69)$ & 0.02 \\
\hline $60-$ & 217 & $33(15.21,10.70-20.69)$ & 217 & $29(13.36,9.14-18.63)$ & 0.68 \\
\hline $70-$ & 92 & $28(30.43,21.27-40.90)$ & 95 & $27(28.42,1.96-38.60)$ & 0.87 \\
\hline \multicolumn{6}{|l|}{ Gender } \\
\hline Male & 520 & $48(9.23,6.88-12.05)$ & 500 & $52(10.40,7.86-13.41)$ & 0.60 \\
\hline Female & 506 & $46(9.09,6.73-11.94)$ & 1029 & $112(10.88,9.05-12.95)$ & 0.33 \\
\hline \multicolumn{6}{|c|}{ Rushan county } \\
\hline Total & 1022 & $389(38.06,35.07-41.19)$ & 1025 & $407(39.71,36.70-42.78)$ & 0.47 \\
\hline \multicolumn{6}{|l|}{ Age (yrs) } \\
\hline $0-$ & 67 & $5(7.46,2.47-16.56)$ & 73 & $15(20.55,11.98-31.62)$ & 0.027 \\
\hline $30-$ & 74 & $25(33.78,23.19-45.18)$ & 78 & $26(33.33,23.06-44.92)$ & 1.00 \\
\hline $40-$ & 234 & $95(40.60,34.25-47.19)$ & 234 & $94(40.17,33.84-46.76)$ & 1.00 \\
\hline $50-$ & 337 & $132(39.17,33.92-44.60)$ & 340 & $139(40.88,35.61-46.76)$ & 0.70 \\
\hline $60-$ & 226 & $103(45.58,38.96-52.31)$ & 225 & $100(44.44,37.84-51.20)$ & 0.85 \\
\hline 70- & 84 & $29(34.52,24.48-45.69)$ & 75 & $33(44.00,32.55-55.94)$ & 0.26 \\
\hline \multicolumn{6}{|l|}{ Gender } \\
\hline Male & 516 & $216(41.86,37.56-46.25)$ & 525 & $229(43.62,39.33-47.98)$ & 0.57 \\
\hline Female & 506 & $173(34.19,30.06-38.50)$ & 500 & $178(35.60,31.40-39.97)$ & 0.64 \\
\hline
\end{tabular}

\# Comparison between HBsAg positive and negative participants 
Table 3 Prevalence of anti-HEV IgG among HBsAg-positive participants by clinical types in Rushan county and Zhangqiu county, Shandong province, China

\begin{tabular}{lllll}
\hline County & Clinical type & Number detected & HEV IgG(+) Number $(\%, 95 \% C l)$ & $53(8.05,6.09-10.40)$ \\
\hline Zhangqiu & HBV carrier & 658 & $9(8.82,4.11-16.09)$ \\
& Chronic case & 102 & $0(0.00,0-15.44)$ \\
& Cirrhosis case & 22 & $0(0.00,0-97.5)$ \\
Rushan & HCC case & 1 & $314(37.47,34.18-40.85)$ \\
& HBV carrier & 838 & $30(40.54,29.27-52.59)$ \\
& Chronic case & 74 & $3(37.50,8.52-75.51)$ \\
& Cirrhosis case & 8 & $3(100.00,29.24,100.00)$
\end{tabular}

HBV hepatitis B virus, HCC hepatocellular carcinoma

In the $\mathrm{CHB}$ group, the positive rate of $\mathrm{HBeAg}$ among anti-HEV IgG $(+)$ participants was significantly lower than the rate among anti-HEV IgG (-) participants (17.18\% vs $24.54 \%, P=0.001$ ), and the same trend was found in the proportion of participants with $\mathrm{HBV}$ DNA $>10^{3}$ copies $/ \mathrm{ml}(32.92 \%$ vs $40.38 \%, P=0.011)$. No significant difference was found between the participants positive for anti-HEV IgG and negative for anti-HEV IgG in the proportions of participants with elevated ALT level and the liver damage identified by ultrasound $(P>0.05)$. The details are shown in Table 4.

\section{Anti-HEV IgM seroprevalence among HBsAg-positive individuals}

Only one participant was positive for anti-HEV IgM in $\mathrm{CHB}$ group in Zhangqiu and the positive rate was $0.1 \%$ (95\% CI: $0.002-0.54$ ). The corresponding rate was $1.57 \%$ (16/1022, 95\% CI: 0.90-2.53) in Rushan, which was much higher than the rate in Zhangqiu $(P<0.001)$. The positive rate of IgM in Rushan was not statistically significant by age, gender and clinical types $(P>0.05)$. HEV RNA has been tested for all serum positive for anti-HEV

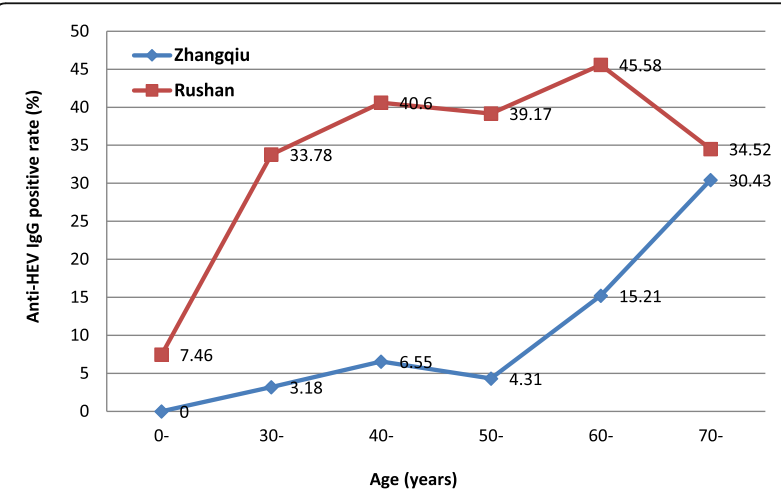

Fig. 2 Anti-HEV lgG seroprevalence by age among HBsAg-positive participants in Zhangqiu county and Rushan county, Shandong province, China
IgM, but none was positive. The details are shown in Table 5.

\section{Comparison of HEV seroprevalence between CHB group and control group}

HEV IgG seroprevalence was $9.16 \%$ and $10.88 \%$ in the $\mathrm{CHB}$ group and the control group, respectively, in Zhangqiu and the corresponding rates were $38.06 \%$ and $39.71 \%$ in Rushan. No significant difference between the two groups was found in either county $(P=0.21$, $P=0.47$, respectively). Age-specific and sex-specific seroprevalence of HEV IgG was similar between the $\mathrm{CHB}$ group and the control group except in agegroups of $0-29$ years and 50-59 years in Zhangqiu and $0-29$ years in Rushan. The positive rate of anti-HEV IgM was $0.1 \%$ and $0.48 \%$ respectively among $\mathrm{CHB}$ group and the control group in Zhangqiu $(P=0.103)$. The corresponding rates in Rushan were $1.57 \%$ and $2.24 \%$ and the difference was not significant too $(P=0.262)$.

Multivariable analysis showed that only age was independently associated with anti-HEV IgG in Zhangqiu $(P<0.05)$, and gender, age and education attainment were independently associated with anti-HEV IgG in Rushan $(P<0.05)$. The status of HBsAg was not independently associated with the status of anti-HEV IgG in either county $(P>0.05)$. The details are shown in Table 6.

\section{Discussion}

Our study showed similar HEV seroprevalence between HBsAg-positive and negative participants in areas with different HEV endemicity. This result is consistent with some previous studies [13, 23], but different from the study by Hoan NX [15]. The reason for the above difference might be due to differences in the participants in these studies. Our study is community-based and most HBsAg-positive participants are HBV carriers, while Hoan NX's study is hospital-based and most participants are chronic hepatitis patients. HEV genotype 4 is predominant in Shandong province [24, 25], and its epidemiology differs from other genotyopes $[5,26]$, so 
Table 4 The results of medical examination in HBsAg-positive participants by anti-HEV IgG

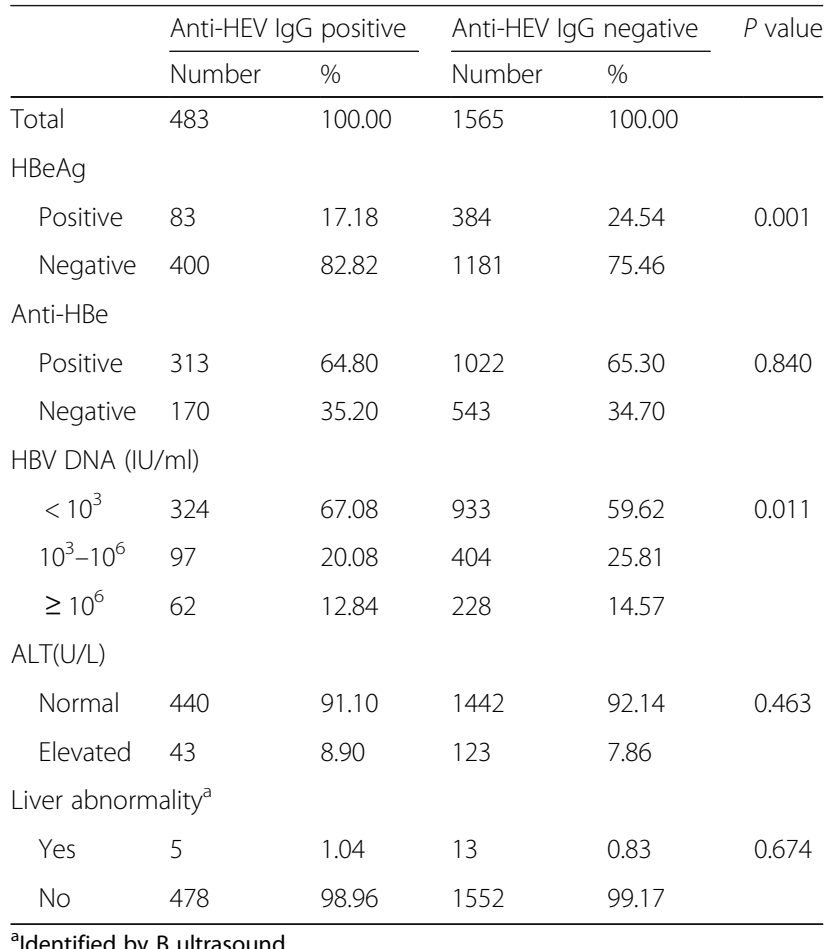

Identified by B ultrasound

Table 5 Seroprevalence of anti-HEV IgM among population with chronic hepatitis B infection in Rushan county, Shandong province, China

\begin{tabular}{lllll}
\hline & $\begin{array}{l}\text { Number } \\
\text { detected }\end{array}$ & $\begin{array}{l}\text { Positive } \\
\text { number }\end{array}$ & $\begin{array}{l}\text { Positive rate } \\
(\%, 95 \%(l)\end{array}$ & $P$ value \\
\hline Total & 1022 & 16 & $1.57(0.90-2.53)$ & -
\end{tabular}

Age group (yrs)

$\begin{array}{lllll}\text { Under } 30 & 66 & 0 & 0(0-5.44) & 0.768 \\ 30-39 & 79 & 1 & 1.26(0.03-6.85) & \\ 40-49 & 242 & 6 & 2.48(0.92-5.32) & \\ 50-59 & 336 & 5 & 1.49(0.48-3.44) & \\ 60-69 & 211 & 3 & 1.42(0.29-4.10) & \\ \text { Above } 70 & 88 & 1 & 1.14(0.03-6.17) & \\ \text { Gender } & & & & \\ \text { Male } & 516 & 8 & 1.55(0.67-3.03) & 0.969 \\ \text { Female } & 506 & 8 & 1.58(0.68-3.09) & \\ \text { Clinical type } & & & & \\ \text { HBV carrier } & 838 & 12 & 1.43(0.74-2.49) & 0.060^{\#} \\ \text { Chronic cases } & 74 & 0 & 0(0-4.86) & \\ \text { Cirrhosis } & 8 & 0 & 0(0-36.94) & \\ \text { HCC } & 3 & 1 & 33.33(0.84-90.57) & \end{array}$

HBV hepatitis B virus, HCC hepatic cellular cancer

\# Fisher's exact test

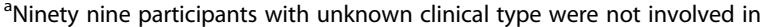
the analysis our finding should be further studied in other areas with different HEV genotypes.

Our study has provided the preliminary evidence for high incidence of HBV-HEV superinfection, in HEV hyper-endemic areas. According to our study, positive results for anti-HEV IgG were found approximately among $40 \%$ of HBsAg-positive persons in Rushan. In China, most chronic HBV infections occur at birth or early childhood, while most HEV infections occur in adults [18]. So it is most likely that HEV infection in our study participants had occurred after HBV infection. Although the duration of the persistence of anti-HEV IgG is still unclear, it is sure not to be life-long [27, 28]. Given this fact, the real seroprevalence of HEV among HBsAg-positive participants might be higher than what we observed in the study.

The detection of anti-HEV IgM could give the direct evidence of acute hepatitis $E$ infection among persons with chronic HBV infection. Although the positive rate of anti-HEV IgM was very low among HBsAg-positive participants in Rushan in our study (only 1\%), it suggests a high risk to attack HEV acute infection among HBsAgpositive patients in the county because this result came from a cross-section study instead of a cohort study.

Some studies showed that HEV infection could result in severe disease in patients with underlying $\mathrm{CHB}$ even liver failure $[8,29-31]$, but the other obtained the opposite conclusion [32]. We did not find more active HBV replication and more severe live damage in $\operatorname{HBsAg}(+)$, anti-HEV $\operatorname{IgG}(+)$ participants than in $\operatorname{HBsAg}(+)$, anti-HEV $\operatorname{IgG}(-)$ participants in the present study. However, it must be noted that most participants were HBV carriers in our study, while most previous studies were conducted among patient with chronic hepatitis or in cirrhotic patients.

Hepatitis E vaccine was licensed in China in 2011 and is the unique commercially available hepatitis $\mathrm{E}$ vaccine in the world till now [33]. The immunogenicity and safety of hepatitis $E$ vaccine has been documented in HBV carriers [34], but no similar studies are available among $\mathrm{CHB}$, cirrhosis and HCC patients. Given the fact that most $\mathrm{CHB}$ patients develop from $\mathrm{HBV}$ carriers and the long-lasting anti-HEV IgG induced by hepatitis $\mathrm{E}$ vaccine has been documented [35], hepatitis $\mathrm{E}$ vaccine is recommended to $\mathrm{HBV}$ carriers to prevent HBV-HEV superinfection, especially in HEV hyperendemic areas.

Two counties with different HEV prevalent level were included in the study, giving the study more depth and improved the generalisability of the findings. However, due to the community-based design of the study, most HBsAg-positive participants were carriers in our study and the conclusions should be further documented in clinical cases. 
Table 6 Multivariable analysis of the risk factors associated with anti-HEV IgG in Zhangqiu county and Rushan county, Shandong province, China

\begin{tabular}{|c|c|c|c|c|c|c|}
\hline & \multicolumn{3}{|l|}{ Zhangqiu } & \multicolumn{3}{|l|}{ Rushan } \\
\hline & Participant number & $P$ & OR $(95 \% \mathrm{Cl})$ & Participant number & $P$ & OR $(95 \% \mathrm{Cl})$ \\
\hline \multicolumn{7}{|l|}{ Gender } \\
\hline Male & 1049 & Ref. & Ref. & 1041 & Ref. & Ref. \\
\hline Female & 1006 & 0.05 & $0.72(0.52,0.98)$ & 1006 & $<0.001$ & $0.71(0.58,0.86)$ \\
\hline \multicolumn{7}{|l|}{ Age (yrs) } \\
\hline Under 30 & 97 & Ref. & Ref. & 138 & Ref. & Ref. \\
\hline $30-39$ & 331 & 0.54 & $0.71(0.24,2.10)$ & 158 & $<0.001$ & $3.38(1.87,6.11)$ \\
\hline $40-49$ & 559 & 0.46 & $1.45(0.54,3.88)$ & 479 & $<0.001$ & $4.64(2.74,7.86)$ \\
\hline $50-59$ & 460 & 0.41 & $1.53(0.56,4.17)$ & 667 & $<0.001$ & $4.17(2.49,6.99)$ \\
\hline $60-69$ & 396 & 0.02 & $3.22(1.18,8.73)$ & 433 & $<0.001$ & $5.47(3.20,9.35)$ \\
\hline Above 70 & 212 & $<0.001$ & $8.62(3.08,24.15)$ & 172 & $<0.001$ & $4.49(2.45,8.22)$ \\
\hline \multicolumn{7}{|l|}{ Education attainment } \\
\hline Illiteracy & 227 & Ref. & Ref. & 115 & Ref. & Ref. \\
\hline Primary school & 739 & 0.246 & $1.32(0.83,2.09)$ & 560 & 0.025 & $1.66(1.06,2.60)$ \\
\hline Junior middle school & 972 & 0.676 & $1.12(0.64,1.96)$ & 1121 & 0.037 & $1.63(1.03,2.58)$ \\
\hline Senior middle school and above & 117 & 0.715 & $1.18(0.48,2.92)$ & 251 & 0.033 & $1.76(1.04,2.96)$ \\
\hline \multicolumn{7}{|c|}{ Occupation about swine laughter or selling } \\
\hline Yes & 11 & Ref. & Ref. & 61 & Ref. & Ref. \\
\hline No & 2044 & 0.122 & $0.29(0.06,1.39)$ & 1986 & 0.654 & $1.13(0.66,1.93)$ \\
\hline \multicolumn{7}{|c|}{ Occupation about seafood cultivation, processing or selling } \\
\hline Yes & 0 & - & - & 43 & Ref. & Ref. \\
\hline No & 2055 & - & - & 2004 & 0.103 & $0.59(0.31,1.11)$ \\
\hline \multicolumn{7}{|l|}{ Wash hands before dining } \\
\hline$\geqq 2$ times per day & 2015 & Ref. & Ref. & 1877 & Ref. & Ref. \\
\hline ఏone time per day & 40 & 0.506 & $0.61(0.14,2.63)$ & 170 & 0.984 & $1.00(0.72,1.39)$ \\
\hline \multicolumn{7}{|l|}{ Drinking unboiled water } \\
\hline$\geqq 3$ times per week & 51 & Ref. & Ref. & 143 & Ref. & Ref. \\
\hline 1-2 times per week & 417 & 0.637 & $1.32(0.42,4.12)$ & 214 & 0.12 & $0.69(0.44,1.09)$ \\
\hline Less than once per week & 1587 & 0.673 & $1.27(0.42,3.87)$ & 1690 & 0.6 & $0.91(0.63,1.31)$ \\
\hline \multicolumn{7}{|l|}{ Eating outside } \\
\hline$\geqq 3$ times per week & 94 & Ref. & Ref. & 98 & Ref. & Ref. \\
\hline 1-2 times per week & 611 & 0.926 & $1.04(0.47,2.29)$ & 140 & 0.924 & $0.97(0.55,1.72)$ \\
\hline Less than once per week & 1350 & 0.644 & $0.83(0.38,1.81)$ & 1809 & 0.34 & $1.25(0.79,1.96)$ \\
\hline \multicolumn{7}{|l|}{ Chronic hepatitis B infection } \\
\hline Yes & 1026 & Ref. & Ref. & 1022 & Ref. & Ref. \\
\hline No & 1029 & 0.187 & $1.23(0.90,1.68)$ & 1025 & 0.609 & $1.05(0.87,1.26)$ \\
\hline
\end{tabular}

\section{Conclusions}

The HEV seroprevalence is similar between HBsAgpositive and HBsAg-negative participants in the same area. The risk of HBV-HEV superinfection could vary greatly in different areas and the HBsAg-positive persons living in HEV hyperendemic areas might be at higher risk for HBV-HEV superinfection. Further study should be conducted to determine the epidemiological characteristics and clinical outcome of HEV-HBV superinfection in HEV hyperendemic areas.

Abbreviations

Anti-HBs: antibody against HBsAg; CHB: Chronic hepatitis B; Cl: Confidential interval; HBsAg: Hepatitis B surface antigen; HBV: Hepatitis B virus: HCC: Hepatocellular carcinoma; HEV: Hepatitis E virus 


\section{Acknowledgments}

We thank our colleagues at Zhangqiu county CDC and Rushan county CDC for their help in questionnaire survey and blood collection.

\section{Funding}

This work was supported by the grants from the Major Project of National Science and Technology (No. 2013ZX10004902), a cooperation project of China Foundation for Hepatitis Prevention and Control, Chinese Center for Disease Control and Prevention and Shandong Provincial Center for Disease Control and Prevention (2014-32-R-019), Taishan Scholar Program of Shandong Province (No. ts20151105) and the Shandong Medical Health Science and Technology Development Programs (2011HD006, 2016ws0386). The funders had no role in study design, data collection and analysis, decision to publish, or preparation of the manuscript.

\section{Availability of data and materials}

The datasets generated during the current study are not publicly available yet, due to privacy concerns and ongoing additional research. Data can be made available for peer review on reasonable request through contacting the corresponding author.

\section{Author's contributions}

LZ contributed to the study design, data collection and the manuscript draft. $\mathrm{BY}$ and YF contributed to the laboratory test. ZJ contributed to the study design, questionnaire investigation and blood sample collection. JLv and JLiu contributed to questionnaire investigation, data entry and analysis. LL, GZ, FW contributed to the study design and data collection. AX contributed to the study design and the manuscript revision. All authors have read and approved the manuscript.

\section{Ethics approval and consent to participate}

The study protocol was approved by the Ethic Committee of Shandong CDC. Written consents were obtained from the participants $\geq 18$ years old or the guardians for those $<18$ years old in this study.

\section{Consent for publication}

Not applicable.

\section{Competing interests}

The authors declare that they have no competing interests.

\section{Publisher's Note}

Springer Nature remains neutral with regard to jurisdictional claims in published maps and institutional affiliations.

\begin{abstract}
Author details
'Academy of Preventive Medicine, Shandong University, Jinan, China. ${ }^{2}$ Shandong Provincial Key Laboratory of Infectious Disease Control and Prevention, Shandong Center for Disease Control and Prevention, Jinan, China. ${ }^{3}$ Rushan Center for Disease Control and Prevention, Weihai, China. ${ }^{4}$ Chinese Center for Disease Control and Prevention, Beijing, China.
\end{abstract}

Received: 7 April 2017 Accepted: 23 January 2018

\section{Published online: 12 February 2018}

\section{References}

1. Kamar N, Bendall R, Legrand-Abravanel F, Xia NS, ljaz S, Izopet J, Dalton HR. Hepatitis E. Lancet. 2012;379(9835):2477-88.

2. Verhoef L, Koopmans M, Duizer E, Bakker J, Reimerink J, Van Pelt W. Seroprevalence of hepatitis E antibodies and risk profile of HEV seropositivity in The Netherlands, 2006-2007. Epidemiol Infect. 2012;140(10):1838-47.

3. Takahashi M, Tamura K, Hoshino Y, Nagashima S, Yazaki Y, Mizuo H, Iwamoto S, Okayama M, Nakamura Y, Kajii E, et al. A nationwide survey of hepatitis E virus infection in the general population of Japan. J Med Virol. 2010;82(2):271-81.

4. Kuniholm MH, Purcell RH, McQuillan GM, Engle RE, Wasley A, Nelson KE. Epidemiology of hepatitis $E$ virus in the United States: results from the third National Health and nutrition examination survey, 1988-1994. J Infect Dis. 2009;200(1):48-56.
5. Hepatitis E vaccine: WHO position paper, May 2015. Releve epidemiologique hebdomadaire 2015, 90(18):185-200.

6. Holla RP, Ahmad I, Ahmad Z, Jameel S. Molecular virology of hepatitis E virus. Semin Liver Dis. 2013;33(1):3-14.

7. Kamar N, Selves J, Mansuy JM, Ouezzani L, Peron JM, Guitard J, Cointault O, Esposito L, Abravanel F, Danjoux M, et al. Hepatitis E virus and chronic hepatitis in organ-transplant recipients. N Engl J Med. 2008;358(8):811-7.

8. Ramachandran J, Eapen CE, Kang G, Abraham P, Hubert DD, Kurian G, Hephzibah J, Mukhopadhya A, Chandy GM. Hepatitis E superinfection produces severe decompensation in patients with chronic liver disease. J Gastroenterol Hepatol. 2004;19(2):134-8.

9. Centers for Disease C. Prevention: investigation of hepatitis E outbreak among refugees - upper Nile, South Sudan, 2012-2013. MMWR Morb Mortal Wkly Rep. 2013;62(29):581-6.

10. Hoad VC, Seed CR, Fryk JJ, Harley R, Flower RLP, Hogema BM, Kiely P, Faddy HM. Hepatitis E virus RNA in Australian blood donors: prevalence and risk assessment. Vox Sang. 2017;112(7):614-21.

11. Roth NJ, Schafer W, Alexander R, Elliott K, Elliott-Browne W, Knowles J, Wenzel JJ, Simon TL. Low hepatitis E virus RNA prevalence in a large-scale survey of United States source plasma donors. Transfusion. 2017;

12. Nasrallah GK, Al Absi ES, Ghandour R, Ali NH, Taleb S, Hedaya L, Ali F, Huwaidy M, Husseini A. Seroprevalence of hepatitis E virus among blood donors in Qatar (2013-2016). Transfusion. 2017;57(7):1801-7.

13. Bayram A, Eksi F, Mehli M, Sozen E. Prevalence of hepatitis E virus antibodies in patients with chronic hepatitis B and chronic hepatitis $C$. Intervirology. 2007;50(4):281-6.

14. Mellgren A, Karlsson M, Karlsson M, Lagging M, Wejstal R, Norder H. High seroprevalence against hepatitis $\mathrm{E}$ virus in patients with chronic hepatitis $\mathrm{C}$ virus infection. J Clin Virol. 2017;88:39-45.

15. Hoan NX, Tong HV, Hecht N, Sy BT, Marcinek P, Meyer CG, Song le H, Toan $\mathrm{NL}$, Kurreck J, Kremsner PG, et al. Hepatitis E virus superinfection and clinical progression in hepatitis B patients. EBioMedicine. 2015;2(12):2080-6.

16. Roux P, Le Gall JM, Debrus M, Protopopescu C, Ndiaye K, Demoulin B, Lions C, Haas A, Mora M, Spire B et al. Innovative community-based educational face-to-face intervention to reduce HIV, hepatitis C virus and other bloodborne infectious risks in difficult-to-reach people who inject drugs: results from the ANRS-AERLI intervention study. Addiction 2016, 111(1):94-106.

17. Liang X, Bi S, Yang W, Wang L, Cui G, Cui F, Zhang Y, Liu J, Gong X, Chen Y, et al. Epidemiological serosurvey of hepatitis B in China-declining HBV prevalence due to hepatitis B vaccination. Vaccine. 2009;27(47):6550-7.

18. Jia Z, Yi Y, Liu J, Cao J, Zhang Y, Tian R, Yu T, Wang H, Wang X, Su Q, et al. Epidemiology of hepatitis $E$ virus in China: results from the third National Viral Hepatitis Prevalence Survey, 2005-2006. PLoS One. 2014;9(10):e110837.

19. Shang Q, Yu J, Xiao D, Xu C, Chen C, Zhang G. The effects of hepatitis E virus superinfection on patients with chronic hepatitis B: a clinicopathological study. Zhonghua nei ke za zhi. 2002;41(10):656-9.

20. Cheng SH, Mai L, Zhu FQ, Pan XF, Sun HX, Cao H, Shu X, Ke WM, Li G, Xu $\mathrm{QH}$. Influence of chronic HBV infection on superimposed acute hepatitis $\mathrm{E}$. World J Gastroenterol. 2013;19(35):5904-9.

21. Yan BYFY, Zhang L, Li MS, Song LZ, Xu Q, Xiao ZQ, Xu AQ. A seroepidemiological investigation on hepatitis $\mathrm{E}$ in Shandong Province. Zhong Hua Ji Bing Kong Zhi Za Zhi. 2013;17(9):785-8.

22. Omata M, Cheng AL, Kokudo N, Kudo M, Lee JM, Jia J, Tateishi R, Han KH, Chawla YK, Shiina S, et al. Asia-Pacific clinical practice guidelines on the management of hepatocellular carcinoma: a 2017 update. Hepatol Int. 2017;11(4):317-70.

23. Pischke S, Gisa A, Suneetha PV, Wiegand SB, Taubert R, Schlue J, Wursthorn K, Bantel H, Raupach R, Bremer B, et al. Increased HEV seroprevalence in patients with autoimmune hepatitis. PLoS One. 2014;9(1):e85330.

24. Zhang L, Yan B, Xu A. A hepatitis E outbreak by genotype 4 virus in Shandong province, China. Vaccine. 2016;34(33):3715-8.

25. Yang D, Jiang M, Jin M, Qiu ZG, Shen ZQ, Cui WH, Wang DN, Gong LF, Li B, Wang XW, et al. Seroprevalence and evolutionary dynamics of genotype 4 hepatitis E virus in Shandong Province, China. World I Gastroenterol. 2014;20(24):7955-63.

26. Teshale EH, Hu DJ. Hepatitis E: epidemiology and prevention. World J Hepatol. 2011;3(12):285-91.

27. Ke WM, Tan D, Li JG, Izumi S, Shinji Y, Hotta H, Yao JL. Consecutive evaluation of immunoglobulin $M$ and $G$ antibodies against hepatitis $E$ virus. J Gastroenterol. 1996;31(6):818-22. 
28. Khuroo MS, Kamili S, Dar MY, Moecklii R, Jameel S. Hepatitis E and longterm antibody status. Lancet. 1993;341(8856):1355.

29. Kumar M, Sharma BC, Sarin SK. Hepatitis E virus as an etiology of acute exacerbation of previously unrecognized asymptomatic patients with hepatitis B virus-related chronic liver disease. J Gastroenterol Hepatol. 2008;23(6):883-7.

30. Ke WM, Li XJ, Yu LN, Lai J, Li XH, Gao ZL, Chen PJ. Etiological investigation of fatal liver failure during the course of chronic hepatitis $B$ in southeast China. J Gastroenterol. 2006:41 (4):347-51.

31. Chow CW, Tsang SW, Tsang OT, Leung VK, Fung KS, Luk WK, Chau TN. Comparison of acute hepatitis $\mathrm{E}$ infection outcome in patients with and without chronic hepatitis B infection: a 10 year retrospective study in three regional hospitals in Hong Kong. J Clin Virol. 2014;60(1):4-10.

32. Blasco-Perrin H, Madden RG, Stanley A, Crossan C, Hunter JG, Vine L, Lane K, Devooght-Johnson N, McLaughlin C, Petrik J, et al. Hepatitis E virus in patients with decompensated chronic liver disease: a prospective UK/French study. Aliment Pharmacol Ther. 2015;42(5):574-81.

33. Li SW, Zhao Q, Wu T, Chen S, Zhang J, Xia NS. The development of a recombinant hepatitis E vaccine HEV 239. Human vaccines \& immunotherapeutics. 2015;11(4):908-14

34. Wu T, Huang SJ, Zhu FC, Zhang XF, Ai X, Yan Q, Wang ZZ, Yang CL, Jiang HM, Liu XH, et al. Immunogenicity and safety of hepatitis $E$ vaccine in healthy hepatitis B surface antigen positive adults. Human vaccines \& immunotherapeutics. 2013;9(11):2474-9.

35. Su YY, Huang SJ, Guo M, Zhao J, Yu H, He WG, Jiang HM, Wang YJ, Zhang XF, Cai JP, et al. Persistence of antibodies acquired by natural hepatitis $E$ virus infection and effects of vaccination. Clin Microbiol Infect. 2017:23(5):336 e331-4.

\section{Submit your next manuscript to BioMed Central and we will help you at every step:}

- We accept pre-submission inquiries

- Our selector tool helps you to find the most relevant journal

- We provide round the clock customer support

- Convenient online submission

- Thorough peer review

- Inclusion in PubMed and all major indexing services

- Maximum visibility for your research

Submit your manuscript at www.biomedcentral.com/submit 